\title{
Building bone tissue: matrices and scaffolds in physiology and biotechnology
}

M. Riminucci ${ }^{1,2}$ and P. Bianco ${ }^{2,3}$

\section{Correspondence \\ P. Bianco \\ Dipartimento di Medicina \\ Sperimentale e Patologia \\ Universita' La Sapienza \\ Viale Regina Elena 324 \\ 00161 Rome \\ Italy \\ E-mail: p.bianco@flashnet.it}

Presented at SIMEC 2002

(International Symposium

on Extracellular Matrix),

Angra dos Reis, RJ, Brazil,

October 7-10, 2002.

Unpublished research included in

this article was supported by

grants from Telethon (E.1029),

AIRC, ASI, and MIUR.

Received February 5, 2003

Accepted June 3, 2003

\author{
${ }^{1}$ Dipartimento di Medicina Sperimentale, \\ Universita' dell'Aquila, Rome, Italy \\ 2Parco Scientifico Biomedico San Raffaele, Rome, Italy \\ ${ }^{3}$ Dipartimento di Medicina Sperimentale e Patologia, \\ Universita' La Sapienza, Rome, Italy
}

Abstract

Deposition of bone in physiology involves timed secretion, deposition and removal of a complex array of extracellular matrix proteins which appear in a defined temporal and spatial sequence. Mineralization itself plays a role in dictating and spatially orienting the deposition of matrix. Many aspects of the physiological process are recapitulated in systems of autologous or xenogeneic transplantation of osteogenic precursor cells developed for tissue engineering or modeling. For example, deposition of bone sialoprotein, a member of the small integrin-binding ligand, N-linked glycoprotein family, represents the first step of bone formation in ectopic transplantation systems in vivo. The use of mineralized scaffolds for guiding bone tissue engineering has revealed unexpected manners in which the scaffold and cells interact with each other, so that a complex interplay of integration and disintegration of the scaffold ultimately results in efficient and desirable, although unpredictable, effects. Likewise, the manner in which biomaterial scaffolds are "resorbed" by osteoclasts in vitro and in vivo highlights more complex scenarios than predicted from knowledge of physiological bone resorption per se. Investigation of novel biomaterials for bone engineering represents an essential area for the design of tissue engineering strategies.

\section{The extracellular matrix of bone}

For decades, attention devoted to the biology of the extracellular matrix (ECM) of bone has been centered on the quest for unique properties thereof, which would explain its unique ability to mineralize in a highly controlled fashion. Originally, the driving idea was that one or more protein species produced in bone but not in other connective tissues would act as tissue-specific inducers,
Key words

- Extracellular matrix

- Bone matrix

- Bone formation

- Biomaterials
- Tissue engineering

$\ldots \ldots \ldots \ldots \ldots \ldots$ 
partment of bone $(1,2)$, and thus not amenable to extraction by usual denaturing agents. Identification of a number of boneenriched noncollagenous proteins and cognate genes ensued, which was later followed by the development of a number of transgenic and knockout models developed with the aim of identifying the specific biological function of individual proteins.

Today, the original idea of the mechanistic relationship between bone proteins and mineralization is in need of significant revision. Most of the proteins originally thought to be unique of the bone ECM have been proven to be expressed in other tissues as well, whereas, ironically enough, a role for osteocalcin (the only protein still reasonably assumed to be bone specific) in bone mineralization has been dispelled by the regular occurrence of bone mineralization in osteocalcin-deficient mice (3). A single well-defined function has not been identified conclusively for any of the bone-enriched noncollagenous proteins. Nonetheless, a number of unexpected biological events in which bone noncollagenous proteins are involved have emerged and are currently the focus of intensive investigation. Many of these events have revealed complexities of bone physiology which were not accounted for by the original, simplistic idea of a bone-specific mineral nucleator and also exceed the limits of biomineralization to extend into cell migration, angiogenesis, assembly of the matrix, maintenance of its mechanical properties, cell-matrix-interaction, and more.

A detailed discussion of the biochemistry of bone matrix can be found elsewhere (4). Ninety percent of the organic matrix of bone is made up by collagen type I, and 10\% by a variety of noncollagenous proteins. The ratio of collagen to noncollagen protein in bone is highly variable throughout the different physiological scenarios of bone formation (from embryonic development to adult remodeling to aging, Ref. 5) and reflects specific changes in the secretory func- tion of the bone-producing cells, the osteoblasts. Primary embryonic bone has a much lower collagen-to-noncollagen ratio compared to postnatal secondary bone (reviewed in Ref. 5), and this results in different types of internal organization of the matrix (woven vs lamellar bone). Thus, the composition and structure of the bone matrix is not one and the same under all physiological circumstances, and insights have started to accumulate on the identity of proteins secreted in association with specific physiological settings.

Gene targeting experiments have revealed significant specific roles for individual proteins or families of proteins. Small proteoglycans found in bone $(6,7)$, for example, play a role in regulating the assembly and structure of the collagen fibrils in bone, and their deficiency induced by gene targeting results in reduced bone mass and strength, and abnormalities in collagen fibrils similar to those found in Ehlers-Danlos syndromes in a variety of connective tissues (8). Small integrin-binding ligand, N-linked glycoproteins include osteopontin and bone sialoprotein (BSP), which are closely related to each other in terms of structure and post-translational modifications (4,9-11). Both feature an integrin-binding RGD motif and are involved in cell-matrix interactions. Osteopontin is widely distributed in different tissues, whereas BSP is highly enriched in bone and skeletal cartilages, is expressed in the human trophoblast (12), and is ectopically expressed in a variety of malignant epithelial cancers (13-15), but not in the cognate normal tissues. In bone, BSP is expressed by fully mature osteogenic cells (Figure 1A) competent to deposit a mineralizing matrix (12), but only during early phases of de novo bone formation (16). Extracellular BSP localizes to newly formed mineralizing bone matrix, and at the electron microscope level, its distribution spatially and temporally coincides with nascent mineral deposits (17), with some of which bone cells establish close contacts (Figure 1B). In systems in 
which mineralization is impaired, such as chick embryos incubated in vitro in the absence of the shell (which naturally supplies the calcium necessary for bone mineralization), BSP is abundantly expressed in competent cells, but not deposited in the ECM (Riminucci M, Gentili C, Cancedda R and Bianco $\mathrm{P}$, unpublished results). In vitro, BSP secreted by osteoblast-like cells is localized to focal adhesions and possibly other adhesion structures (Figure 1C) (Riminucci M and Bianco P, unpublished data).

\section{Scaffolds in physiological bone formation}

Deposition of bone is a highly oriented, polarized phenomenon. Osteoblasts seem to know where to deposit bone and where not to. For example, this allows the new bone built by osteoblasts during bone remodeling to go and fill the space generated by the previous resorption phase, and not elsewhere. This ensures not only a homeostatic balance between resorption and formation, but also the restoration and preservation of the structural and morphological layout of existing bone tissue. The high degree of polarity of bone deposition clashes with the notion that osteoblasts, like all connective tissue cells, have not evolved efficient mechanisms for maintaining cell polarity and polarized secretion. In epithelial cells, polarized secretion is made possible by the existence of polarized domains of the plasma membrane, which in turn are established and stabilized through the interaction with a basement membrane and the segregation of membrane domains by systems of tight junctions. Osteoblasts do not reside upon a basement membrane and do not establish systems of tight junctions. How then do bone cells deposit bone in a polarized fashion without being polarized cells? They do so by using scaffolds and templates which direct deposition of matrix proteins that are secreted in a nonpolarized fashion (18).

\section{Creation of a scaffold in de novo bone formation}

In physiology, bone formation occurs a) on preexisting bone surfaces, or b) on preexisting nonosseous but mineralized surfaces, or c) de novo in the context of unmineralized tissue. Instances a) and b) represent the formation of bone tissue on a preexisting mineralized scaffold, which accounts for most of the total bone formation occurring during growth, and for all bone formation occurring after skeletal growth has ceased with sexual maturity. De novo bone formation has unique biochemical features which distinguish it from bone formation occurring under different circumstances. BSP is specifically expressed by osteoblasts depositing bone de
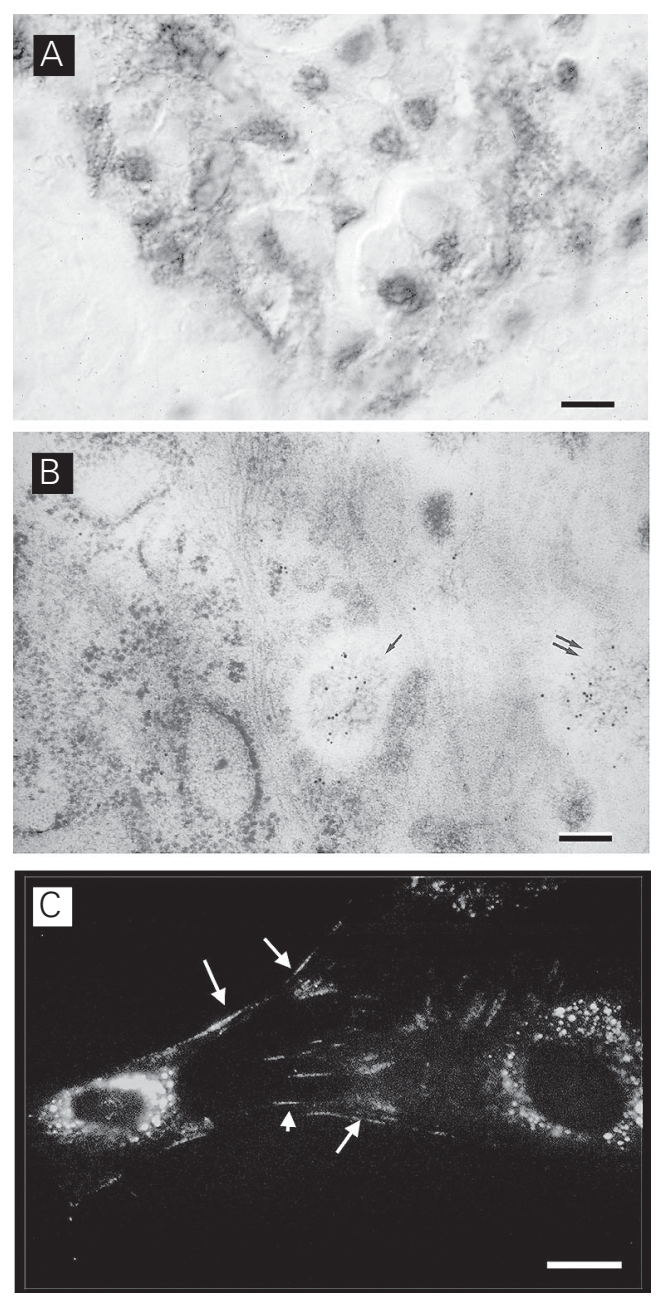

Figure 1. Expression and deposition of bone sialoprotein (BSP) by bone cells in vivo and in vitro. $A$, De novo bone formation in a 17-day rat embryo, with BSP immunolocalization. BSP is observed in the Golgi apparatus of mature osteoblasts and in the nascent bone matrix. $B$, Electron microscopy immunolocalization of BSP. BSP is localized to discrete structures (double arrows) in the nascent bone matrix, corresponding to early mineral deposits. The single arrow points to one such structure in close contact with an osteoblast. $C$, Primary culture of newborn rat calvarial cells, with BSP immunofluorescence. Note BSP localization to intracellular secretory granules and to adhesion structures (arrows). Bars $=8 \mu \mathrm{m}$ (A); $0.1 \mu \mathrm{m}(\mathrm{B}) ; 10 \mu \mathrm{m}(\mathrm{C})$. 
novo (Figure 2A), and much less or not at all by osteoblasts adding bone to preexisting bone (16). De novo bone formation is the only scenario in which no preexisting scaffold is available to guide the deposition of new bone matrix synthesized and deposited by osteoblasts. Interestingly, the generation of a scaffold is the first event in de novo bone formation. Deposition of the first bone matrix at any site of de novo bone formation takes place between rows of cells facing each other (vis-à-vis cells) (19). This allows
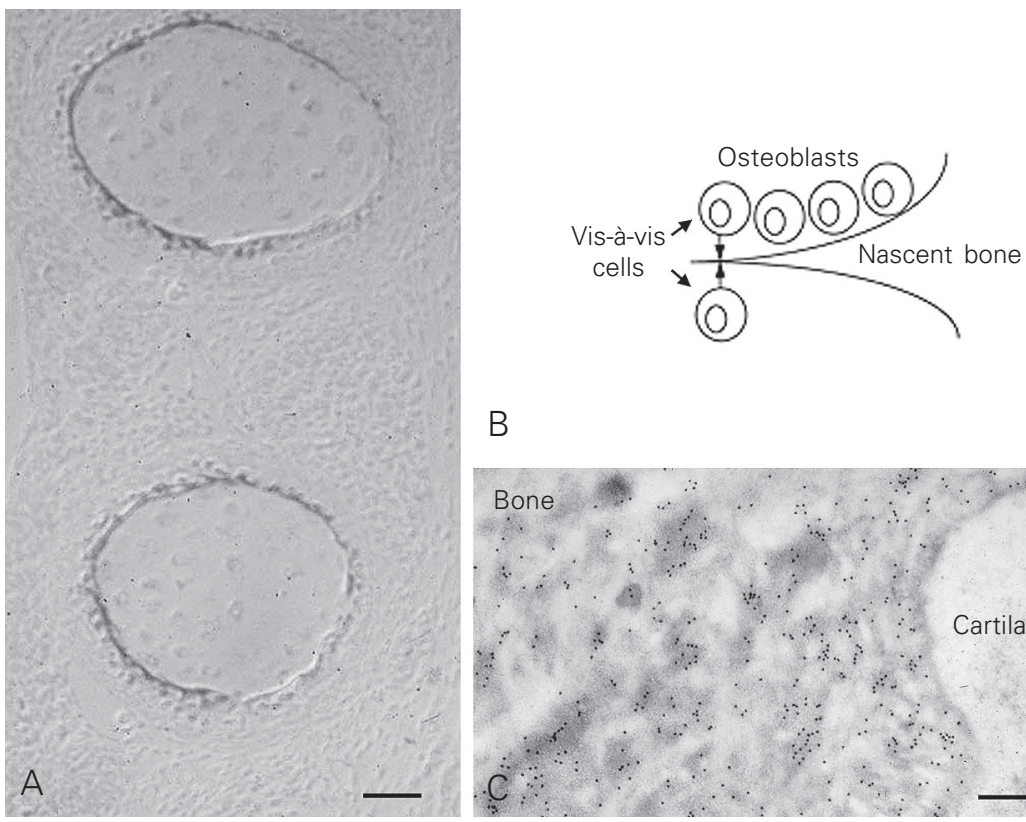

B

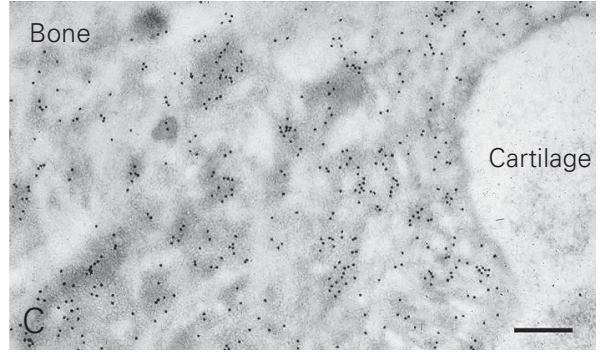

Figure 2. A, Deposition of a bone sialoprotein (BSP)-enriched matrix at the sites of nascent bone formation in rat embryonic ribs. Rings of BSP-rich matrix surround the cartilage anlagen of the ribs. At these sites, BSP immunoreactivity and early mineral deposits codistribute in space and time. Both osteoblasts located on the outer surface of the cartilage anlage and peripheral hypertrophic chondrocytes located at the edge of the anlage ("borderline" chondrocytes) contribute to the deposition of the nascent mineralizing matrix. A BSP-rich material forms the interface between bone and cartilage. B, Diagram illustrating the generation of a scaffold at sites of de novo bone formation. Rows of cells competent to deposit a mineralizing matrix are arranged vis-à-vis. Secretion of a noncollagenous matrix enriched in BSP results in a local enrichment in mineral nucleators in the space between the facing rows of cells. Mineral deposits form rapidly in this milieu and adsorb osteoblastproduced matrix proteins, thus determining the polarized deposition of the products of nonpolarized secretion. These events "prime" the subsequent deposition of collagen-rich bone matrix. Once a template (scaffold) is generated in this way, subsequent deposition of bone remains spatially oriented. C, Electron microscopy immunolocalization of BSP in an endochondrally formed bone trabecula in the primary spongiosa of growing bone. Here, bone is formed on the surface of a preexisting core of mineralized cartilage (cartilage). Note that BSP immunolabeling marks the cement line at the interface of bone and cartilage, and also material (called cement) found between collagen fibrils. In this Lowicryl K4M section, collagen fibrils appear as electron-lucent space. Bars $=20 \mu \mathrm{m}(\mathrm{A}) ; 0.2 \mu \mathrm{m}(\mathrm{C})$. the space between facing rows of cells to become highly enriched in proteins otherwise secreted in a nonpolarized fashion. Mineral is deposited at the same time and in direct physical association with the deposition of certain bone proteins, first and foremost BSP. Electron microscopy analysis reveals that early mineral clusters cannot be physically distinguished by early spots of newly deposited BSP $(17,19)$. The creation of mineral clusters at nascent osteogenic sites further promotes the adsorption of osteoblast-secreted proteins, thus establishing a preferential direction for bone deposition in spite of the lack of determinants for polarized secretion of matrix proteins. Subsequent directional accretion of matrix onto the nascent sites then becomes polarized by default once a scaffold has been created (Figure 2B).

\section{Deposition of bone on a preexisting scaffold in physiology}

Endochondral bone formation provides the easiest scenario in which to seek a simplified representation of the nature and temporal sequence of events characterizing the interaction of osteogenic cells with a preexisting mineralized scaffold. The scaffold is provided by mineralized cartilage cores which have formed at the climax of growth plate maturation. On these cores, newly differentiated osteoblasts deposit temporary bone, fated to be remodeled into secondary trabecular bone. A specific histological structure - the cement line - separates the cartilage core from the primary bone which is deposited onto it. The cement line found in the trabeculae of the endochondrally formed primary spongiosa is structurally and chemically identical to cement lines found in secondary and even postnatal bone, where they physically mark the reversal of a resorption phase to a new formation phase. Cement lines do not contain collagen type I or type II, mineralize to a higher extent than bone, and 
are highly enriched in BSP (20). Since cement lines are formed by the first matrix which is laid down during bone formation, their enrichment in BSP is a further instance of the role of this protein in de novo bone formation. As bone formation progresses, increasing amounts of collagen are produced by osteoblasts and layered onto the BSP-rich cement line. Among collagen fibrils, a structural phase with electron microscopic, cytochemical and immunocytochemical characteristics identical to those of the cement line is recognizable (Figure 2C). To emphasize this similarity in structure and nature, this phase (a true structurally defined noncollagenous phase in bone) has been named cement (20).

\section{Scaffolds in bone tissue engineering - evolution of a concept}

Attempts at tissue engineering of bone long precede the current implementation of stem cell-based technologies. Before methods became available for isolating, expanding and culturing osteogenic progenitor cells to be used for bone reconstruction, scaffolds were used alone to guide and promote regeneration of bone tissue after trauma or extirpative surgery (21-26). Most of the materials used under these circumstances were hydroxyapatite-based (27-33), and a crucial requirement of their design and use was that their internal structure should be such as to accommodate the ingrowth of blood vessels, and to guide the subsequent deposition of bone in a way that would ultimately mimic the haversian structure of normal compact bone. (Macro)porosity of the material was thus an important characteristic. Hydroxyapatite-based materials are osteoconductive, meaning that they lead to bone deposition, provided that fully differentiated and competent osteogenic cells are available at the site of implantation. It is important to distinguish osteoconductivity from osteoinductivity, which means the ability of a given chem- ical species to induce de novo differentiation of competent osteogenic cells from nonosteogenic and uncommitted cells - a property only ascribed in biology to members of the bone morphogenetic protein family. Hydroxyapatite is osteoconductive because it adsorbs osteogenic growth factors from the local milieu and from the circulation, thus creating suitable local conditions for bone formation when implanted in an osseous environment. It is not osteoinductive because it is not sufficient to induce differentiation of osteogenic cells when implanted in a nonosseous environment such as skin or muscle. In addition, rigid hydroxyapatite materials fulfill the requirement of bone cells for a template onto which to deposit bone, and provide some mechanical resilience at the site of implantation, even though the fragility and inelasticity of hydroxyapatite ceramic (HAC)-based carriers warrants the use of internal fixation whenever a HAC device is used for restoration of a loadbearing skeletal segment.

\section{Integration, disintegration, and resorption of HAC scaffolds}

Ideally, a HAC carrier, whether used alone or in combination with cells, should be easily integrated in bone, and also resorbable and amenable to gradual replacement by newly formed bone. Curiously, a rigorous and consistent definition of "integration" is not easily identified in the literature. On the other hand, common concepts of resorbability of HAC carriers are not based on rigorous experimental assessment. Integration of a HAC-based material used for bone grafting implies the establishment of a structural and functional continuity between the implanted material and the bone surfaces available at the implantation site (34). It also implies, however, the establishment of the same continuity between HAC surfaces available at the implantation site and the bone which is newly deposited after implantation, either 
by resident osteogenic cells, or by osteogenic cells included in a "biologized" implant (that is, a HAC/cell construct).

Integration of bone and $\mathrm{HAC}$ at the microscopic level reveals unexpected complexities. Boyde et al. (35) investigated the longterm fate of large porous HAC cylinders which were implanted in a weight-bearing bone of large mammals in order to promote repair of an experimental critical size defect. This study revealed that integration of HAC into bone occurs at multiple dimensional levels, reflecting different orders of porosity of the material employed. Bone fills macropores (size of the order of hundreds of microns) as well as micropores down to the size of $2 \mu \mathrm{m}$. Thus, bone cells are able to fill gaps and spaces in the HAC structure that are one order of magnitude smaller than their own size, as if bone matrix was deposited in a fluid state before solidifying into a mineralized phase. In addition, continuing mechanical effects on the implanted material generate breaks and clefts within the material. This generates additional HAC surfaces available for osteoconduction, and progressively smaller portions of HAC become incorporated into bone. A disintegration mechanism thus boosts integration of the HAC.

Resorbability of HAC-based materials is commonly thought to reflect chemical composition (relative content of hydroxyapatite vs tricalcium phosphate) and hydroxyapatite

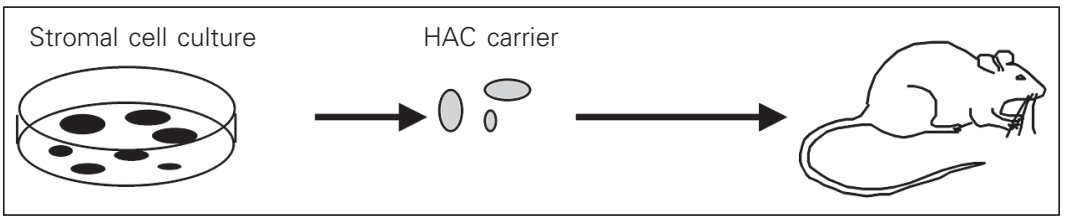

Figure 3. The principle of bone reconstruction using stromal stem cells and biomaterial scaffolds. Stromal stem cells (skeletal stem/progenitor cells) are isolated from the bone marrow as adherent clonogenic cells. Strains obtained from ex vivo expansion are then loaded onto suitable carriers (most of which are hydroxyapatite ceramic (HAC)-based materials available either as solid structures or granular powders) and transplanted into experimental animals. Ectopic transplantation (e.g., in the subcutaneous tissue of immunocompromised mice) is used to assay the differentiation potential of the cell lines; orthotopic transplantation in bone (e.g., at the site of an experimentally created bone gap) of similar $\mathrm{HAC/cell} \mathrm{constructs} \mathrm{prepared} \mathrm{with} \mathrm{autologous} \mathrm{cells} \mathrm{is} \mathrm{used} \mathrm{in} \mathrm{preclinical} \mathrm{models} \mathrm{of} \mathrm{bone}$ tissue engineering. crystal size, which in turn is a function of the sintering temperature. However, adequate investigations of how osteoclasts (the cells involved in resorption of bone and thus envisioned as the HAC-resorbing cells) behave with respect to HAC-based biomaterials in vitro and in vivo are largely missing. The ideal approach involves the use of isolated osteoclasts in a pit resorption assay (36), followed by adequate assessment not only of pit number and diameter but also of pit depth, which significantly affects the actual volume of material which is resorbed (36). Data obtained using this approach (Boyde A and Bianco $P$, unpublished results) reveal specific manners of HAC-osteoclast interaction, which are not accounted for by the simplistic assumption that osteoclasts would deal with HAC in the same manner as they deal with bone. Thus, the manner in which bone cells at large (i.e., both bone-forming and boneresorbing cells) handle HAC-based materials represents an important area for future investigation, at the cross-road of bone cell biology and material science.

\section{Scaffolds and skeletal stem cells - mimicking physiology in tissue engineering}

The recognition of the existence of skeletal stem/progenitor cells in the postnatal bone marrow of humans and other mammals has opened important perspectives in bone tissue engineering (37). Skeletal progenitor cells are found among the adherent, clonogenic and fibroblastic cells associated with the bone marrow stroma (38). These cells can be significantly expanded ex vivo (Figure 3 ) in order to generate sufficient numbers of cells competent to differentiate into mature osteoblasts and form new bone upon in vivo transplantation (39-42). Transplantation of about $10^{6}$ such cells in conjunction with suitable carriers in the subcutaneous tissue of immunocompromised mice generates several $\mathrm{mm}^{3}$ of new bone and associated 
tissues (bone marrow) organized in a structural layout closely resembling natural bone histology $(38,43,44)$.

Under these experimental circumstances, transplanted skeletal stem cells recapitulate the formation of bone and marrow in a precisely defined temporal sequence. The deposition of bone precedes the establishment of a suitable hematopoietic stroma and its colonization by blood-borne hematopoietic stem cells. In the resulting "ossicle", a bony and stromal framework of donor origin (i.e., formed by the transplanted cells) harbors a complete hematopoietic tissue formed by host hematopoietic progenitors (45). In the early stages of bone deposition which initiate and trigger the whole process, deposition of BSP is the first recognizable step (Figure 4), much like in normal bone formation (Riminucci M, Corsi A, Quarto R, Cancedda $\mathrm{R}$ and Bianco $\mathrm{P}$, unpublished results). The surface of the carrier is painted with a BSP-enriched layer (cement) which remains detectable upon the subsequent addition of a collagenous phase. An additional common feature of the HAC-bone interface generated upon transplantation of $\mathrm{HAC} /$ progenitor cell constructs is the presence of a more or less regular row of cells adjacent to the scaffold surface and embedded in the newly deposited matrix (Figure 4). Given the nature of BSP as an RGD motif-containing, cell-binding protein, this finding may signify a role of BSP in promoting (and mediating) cell-scaffold interactions in the early phases of deposition of new bone on the HAC material.

Thus, the essential microevents of initial bone formation under natural conditions are duplicated when bone is engineered. Both in natural settings and in bone tissue engineering, bone cells handle a scaffold surface in a similar manner. They deposit a layer of cement, a noncollagenous matrix enriched in BSP (and other cell-binding proteins) as a preliminary step in the deposition of the collagenous matrix. The high affinity of BSP for mineral surfaces probably plays a role in promoting the adsorption of a cell-derived protein phase onto a preexisting mineral surface, and may play a role in creating a mineral surface by nucleating mineral deposition. The resulting organic-inorganic structure provides a template for polarized bone deposition. Thus, mineral itself plays a biological role in guiding bone formation via interactions with cell products and cells themselves.
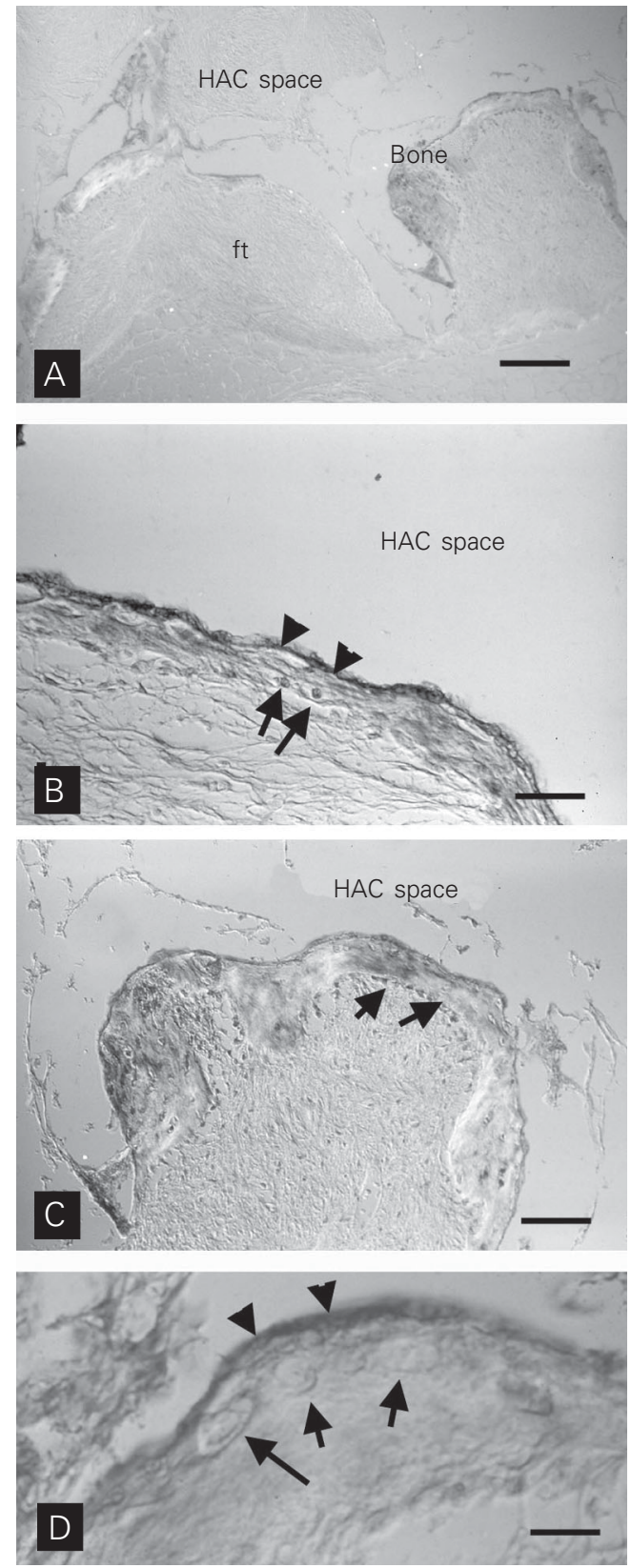

Figure 4. A, Bone formation on the surface of a hydroxyapatite ceramic (HAC)/skeletal stem cell construct which was transplanted into the subcutaneous tissue of an immunocompromised mouse. The tissue formed at the site of transplantation was harvested 2 weeks post-transplant, demineralized, processed for histology, and used for immunolocalization of bone sialoprotein (BSP). Dissolution of the HAC material during decalcification generates empty space (HAC space) which corresponds to the space previously occupied by the material. Bone forms on the surface of the HAC material, and a distinct layer of BSP-enriched matrix marks the HAC/bone interface (B, D, arrowheads). On the growing surface of the newly formed bone, individual osteoblasts are BSP-immunoreactive ( $B, C$, arrows). In D, note several osteocytes (arrows) residing next to the BSP-rich layer (arrowheads). $\mathrm{ft}=$ fibrous tissue . Bars $=200 \mu \mathrm{m}(\mathrm{A}) ; 60 \mu \mathrm{m}(\mathrm{B})$; $100 \mu \mathrm{m}$ (C); $10 \mu \mathrm{m}$ (D). 
Figure 5. A, Low power scanning electron microscopic (SEM) view of a hydroxyapatite ceramic (HAC) sample used for studies in bone tissue engineering. $B_{\text {, }}$ SEM view of a HAC sample retrieved from an intraosseous site 5 months after implantation. Bone has filled HAC pores. Bars $=250 \mu \mathrm{m}(\mathrm{A}) ; 50 \mu \mathrm{m}$ (B).
The need for a template is retained in attempts to reconstruct bone tissue using skeletal stem cells. Local transplantation of skeletal stem cells in conjunction with a suitable physical carrier (Figure 5) represents a major promise for bone repair or augmentation in orthopedics and dentistry $(37,38,43)$. To date, a substantial amount of preclinical investigation indicates the feasibility of the approach. Animal models have been developed in which autologous skeletal stem cells isolated from bone marrow can generate significant amounts of bone orthotopically (i.e., in critical size defects created in bone) (46-49). In these systems, the use of skeletal progenitor cells conveys distinct advantages over the use of the scaffold alone. Bone formation occurs at a faster rate and results in the formation of a com-
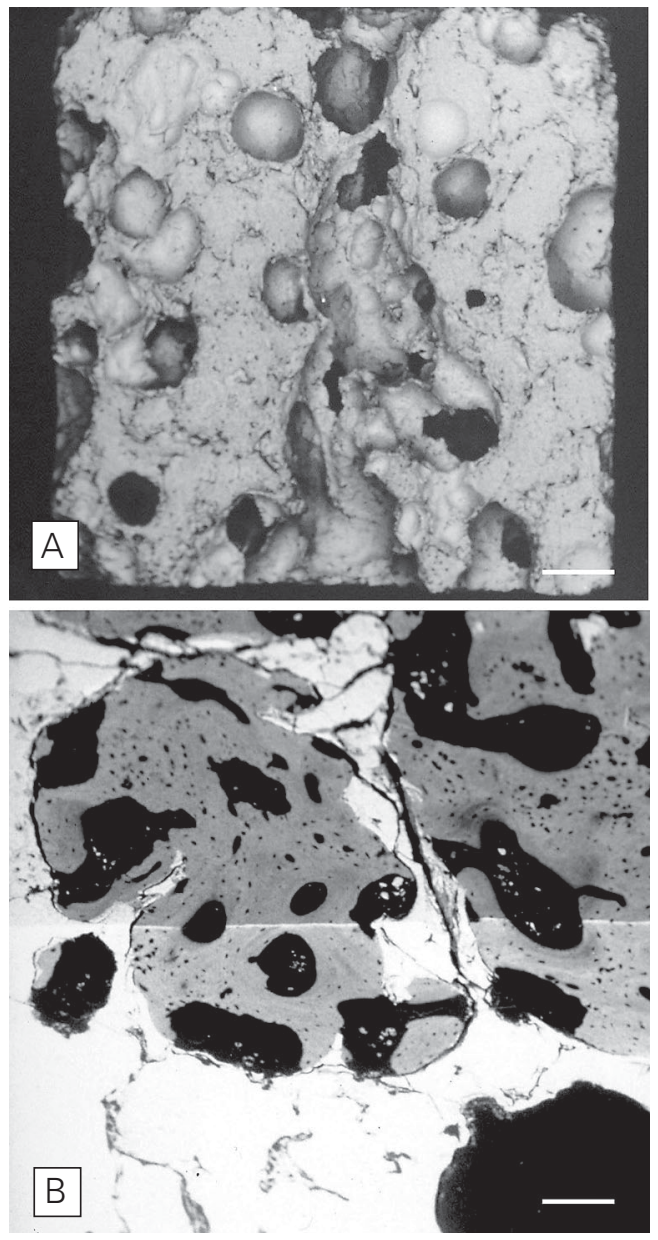

posite bone/HAC phase which is effective in temporary bone repair (46-49). Preliminary clinical observations confirm the significant potential of the approach (50).

The inclusion of stem cell technologies in the current approaches to bone reconstruction brings about novel challenges in the design and conception of scaffolds and carriers. Porosity of the material, traditionally seen as a necessary inherent characteristic, assumes a novel significance in this context, namely as the property whereby a uniform access is granted to cells employed to generate a biotechnological construct. Little work has been done to determine the actual permeability of materials in use with respect to cells suspended in a fluid phase permeating the micropores of the scaffold. More important, materials that are efficient in providing physical support and appropriate geometry for bone formation may not necessarily be endowed with the properties required to ensure stem cell survival. This is particularly relevant when materials are considered for the production of devices to be used in clinical procedures that have to last a very long time, such as those performed in infants or adolescents with skeletal disorders. Experience from separate fields, such as skin reconstruction using epidermal stem cells, has clearly indicated the critical role, in this specific context, of the supporting materials that are used (reviewed in Ref. 37). While the new perspectives opened by stem cell technologies have essentially employed materials conceived for a previous era of tissue engineering, in which autochthonous cells residing at the site of implantation would merely use a biomaterial scaffold, significant innovations have been introduced in the field of bone biomaterial proper. These notably include the design of injectable mineral phases capable of crystallization in vivo, or the design of biological matrices suited to direct cell growth and differentiation locally (reviewed in Ref. 37). Directing efforts towards the development of novel materials in 
view of the specific challenges posed by rapid advances in the field of skeletal stem and progenitor cell biology will undoubtedly be rewarding.

\section{Acknowledgments}

We gratefully acknowledge Alessandro
Corsi, University of L'Aquila, Italy; Ranieri Cancedda and Rodolfo Quarto, Centro Biotecnologie Avanzate, Genoa, Italy; Pamela Gehron Robey, National Institute of Dental and Craniofacial Research, National Institutes of Health, Bethesda, MD, USA, and Alan Boyde, University College London, UK, for valuable collaboration.

\section{References}

1. Termine JD, Belcourt AB, Miyamoto MS \& Conn KM (1980). Properties of dissociatively extracted fetal tooth matrix proteins. II. Separation and purification of fetal bovine dentin phosphoprotein. Journal of Biological Chemistry, 255: 9769-9772.

2. Termine JD, Belcourt AB, Conn KM \& Kleinman HK (1981). Mineral and collagen-binding proteins of fetal calf bone. Journal of Biological Chemistry, 256: 10403-10408.

3. Ducy P, Desbois C, Boyce B et al. (1996). Increased bone formation in osteocalcin-deficient mice. Nature, 382: 448-452.

4. Gehron Robey P \& Bianco P (2002). The cell and molecular biology of bone formation. In: Favus MJ \& Coe FL (Editors), Disorders of Bone and Mineral Metabolism. Lippincott Williams \& Wilkins, Philadelphia, PA, USA, 199-226.

5. Bianco P (1992). Structure and mineralization of bone. In: Bonucci $E$ (Editor), Mineralization in Biological Systems. CRC Press, Boca Raton, FL, USA, 243-268.

6. Fisher LW, Hawkins GR, Tuross N \& Termine JD (1987). Purification and partial characterization of small proteoglycans I and II, bone sialoproteins I and II, and osteonectin from the mineral compartment of developing human bone. Journal of Biological Chemistry, 262: 9702-9708.

7. Fisher LW, Termine JD \& Young MF (1989). Deduced protein sequence of bone small proteoglycan I (biglycan) shows homology with proteoglycan II (decorin) and several nonconnective tissue proteins in a variety of species. Journal of Biological Chemistry, 264: 4571-4576.

8. Corsi A, Xu T, Chen X-D et al. (2002). Phenotypic effects of biglycan deficiency are linked to collagen fibril abnormalities, are synergized by decorin deficiency, and mimic Ehlers-Danlos-like changes in bone and other connective tissues. Journal of Bone and Mineral Research, 17: 1180-1189.

9. Fisher LW, McBride OW, Termine JD \& Young MF (1990). Human bone sialoprotein. Deduced protein sequence and chromosomal localization. Journal of Biological Chemistry, 265: 23447-23451.

10. Kerr JM, Fisher LW, Termine JD, Wang MG, McBride OW \& Young MF (1993). The human bone sialoprotein gene (IBSP): genomic localization and characterization. Genomics, 17: 408-415.

11. Fisher LW, Whitson SW, Avioli LV \& Termine JD (1983). Matrix sialoprotein of developing bone. Journal of Biological Chemistry, 258: 12723-12727.

12. Bianco P, Fisher LW, Young MF, Termine JD \& Gehron Robey $P$ (1991). Expression of bone sialoprotein (BSP) in developing human tissues. Calcified Tissue International, 49: 421-426.

13. Bellahcene A, Merville MP \& Castronovo V (1994). Expression of bone sialoprotein, a bone matrix protein, in human breast cancer.
Cancer Research, 54: 2823-2836.

14. Bellahcene A, Kroll M, Liebens F \& Castronovo V (1996). Bone sialoprotein expression in primary human breast cancer is associated with bone metastases development. Journal of Bone and Mineral Research, 11: 665-670.

15. Bellahcene A, Menard S, Bufalino R, Moreau L \& Castronovo V (1996). Expression of bone sialoprotein in primary human breast cancer is associated with poor survival. International Journal of Cancer, 69: 350-353.

16. Bianco $P$, Riminucci $M$, Bonucci $E$, Termine JD \& Gehron Robey $P$ (1993). Bone sialoprotein (BSP) and osteoblast differentiation: relationship to bromodeoxyuridine incorporation, alkaline phosphatase, and matrix deposition. Journal of Histochemistry and Cytochemistry, 41: 183-191.

17. Bianco P, Riminucci M, Silvestrini G, Bonucci E, Termine JD, Fisher LW \& Gehron Robey P (1993). Localization of bone sialoprotein (BSP) to Golgi and post-Golgi secretory structures in osteoblasts and to discrete sites in early bone matrix. Journal of Histochemistry and Cytochemistry, 41: 193-203.

18. Bianco P, Cancedda FD, Riminucci M \& Cancedda R (1998). Bone formation via cartilage models: the "borderline" chondrocyte. Matrix Biology, 17: 185-192.

19. Riminucci M, Bradbeer JN, Corsi A, Gentili C, Descalzi F, Cancedda R \& Bianco P (1998). Vis-à-vis cells and the priming of bone formation. Journal of Bone and Mineral Research, 13: 1852-1861.

20. Riminucci M, Silvestrini G, Bonucci E, Fisher LW, Gehron Robey P \& Bianco P (1995). The anatomy of bone sialoprotein immunoreactive sites in bone as revealed by combined ultrastructural histochemistry and immunohistochemistry. Calcified Tissue International, 57: 277-284.

21. Bucholz RW, Carlton A \& Holmes R (1989). Interporous hydroxyapatite as a bone graft substitute in tibial plateau fractures. Clinical Orthopaedics, 240: 53-62.

22. Cameron HU, Macnab I \& Pilliar RM (1977). Evaluation of biodegradable ceramic. Journal of Biomedical Materials Research, 11: 179186.

23. Capanna R, Manfrini M, Tigani D \& Giunti A (1991). Tricalcium phosphate and hydroxyapatite ceramics in the surgery of bone tumors: preliminary results. Chirurgia Degli Organi di Movimento, 76: $245-254$.

24. Chappard D, Zhioua A, Grizon F, Basle MF \& Rebel A (1993). Biomaterials for bone filling: comparisons between autograft, hydroxyapatite and one highly purified bovine xenograft. Bulletin de I'Association des Anatomistes, 77: 59-65.

25. Dumbach J, Rodemer H, Spitzer WJ \& Steinhauser EW (1994). 
Mandibular reconstruction with cancellous bone, hydroxyapatite and titanium mesh. Journal of Cranio-Maxillo-Facial Surgery, 22: 151-155.

26. Elsinger EC \& Leal L (1996). Coralline hydroxyapatite bone graft substitutes. Journal of Foot and Ankle Surgery, 35: 396-399.

27. Giannini S, Moroni A, Pompili M, Ceccarelli F, Cantagalli S, Pezzuto V, Trinchese L, Zaffe D, Venturini A \& Pigato M (1992). Bioceramics in orthopaedic surgery: state of the art and preliminary results. Italian Journal of Orthopaedics and Traumatology, 18: 431-441.

28. Holmes RE, Bucholz RW \& Mooney V (1986). Porous hydroxyapatite as a bone-graft substitute in metaphyseal defects. A histometric study. Journal of Bone and Joint Surgery, 68: 904-911.

29. Heise U, Osborn JF \& Duwe F (1990). Hydroxyapatite ceramic as a bone substitute. International Orthopaedics, 14: 329-338.

30. Holmes RE, Bucholz RW \& Mooney V (1987). Porous hydroxyapatite as a bone graft substitute in diaphyseal defects: a histometric study. Journal of Orthopaedic Research, 5: 114-121.

31. Holmes R \& Hagler H (1988). Porous hydroxyapatite as a bone graft substitute in maxillary augmentation. A histometric study. Journal of Cranio-Maxillo-Facial Surgery, 16: 199-205.

32. Jarcho M (1981). Calcium phosphate ceramics as hard tissue prosthetics. Clinical Orthopaedics and Related Research, 157: 259-278.

33. Johnson KD, Frierson KE, Keller TS, Cook C, Scheinberg R, Zerwekh J, Meyers L \& Sciadini MF (1996). Porous ceramics as bone graft substitutes in long bone defects: a biomechanical, histological, and radiographic analysis. Journal of Orthopaedic Research, 14: 351 369.

34. Marcacci M, Kon E, Zaffagnini S et al. (1999). Reconstruction of extensive long bone defects in sheep using porous hydroxyapatite sponges. Calcified Tissue International, 64: 83-90.

35. Boyde A, Corsi A, Quarto R, Cancedda R \& Bianco P (1999). Osteoconduction in large macroporous hydroxyapatite ceramic implants: evidence for a complementary integration and disintegration mechanism. Bone, 24: 579-589.

36. Jones SJ \& Boyde A (1993). Histomorphometry of Howship's lacunae formed in vivo and in vitro: depths and volumes measured by scanning electron and confocal microscopy. Bone, 14: 455-460.

37. Bianco P \& Gehron Robey P (2001). Stem cells in tissue engineering. Nature, 414: 118-121.

38. Bianco P \& Gehron Robey P (2000). Marrow stromal stem cells. Journal of Clinical Investigation, 105: 1663-1668.

39. Friedenstein AJ, Shapiro-Piatetzky II \& Petrakova KV (1966). Osteogenesis in transplants of bone marrow cells. Journal of Embryology and Experimental Morphology, 16: 381-390.

40. Friedenstein AJ, Latzinik NW, Grosheva AG \& Gorskaya UF (1982). Marrow microenvironment transfer by heterotopic transplantation of freshly isolated and cultured cells in porous sponges. Experimental Hematology, 10: 217-227.

41. Goshima J, Goldberg VM \& Caplan Al (1991). The osteogenic potential of cultured-expanded rat marrow mesenchymal cells assayed in vivo in calcium phosphate ceramic blocks. Clinical Orthopaedics, 262: 298-311.

42. Krebsbach PH, Kuznetsov SA, Satomura K, Emmons RV, Rowe DW \& Gehron Robey P (1997). Bone formation in vivo: comparison of osteogenesis by transplanted mouse and human marrow stromal fibroblasts. Transplantation, 63: 1059-1069.

43. Krebsbach PH, Kuznetsov SA, Bianco P \& Gehron Robey P (1999). Bone marrow stromal cells: characterization and clinical application. Critical Reviews in Oral Biology and Medicine, 10: 165-181.

44. Bianco P, Kuznetsov SA, Riminucci M, Fisher LW, Spiegel AM \& Gehron Robey P (1998). Reproduction of human fibrous dysplasia of bone in immunocompromised mice by transplanted mosaics of normal and Gsalpha-mutated skeletal progenitor cells. Journal of Clinical Investigation, 101: 1737-1744.

45. Kuznetsov SA, Krebsbach PH, Satomura K, Kerr J, Riminucci M Benayahu D \& Gehron Robey P (1997). Single-colony derived strains of human marrow stromal fibroblasts form bone after transplantation in vivo. Journal of Bone and Mineral Research, 12: 1335-1347.

46. Ohgushi H, Goldberg VM \& Caplan Al (1989). Repair of bone defects with marrow cells and porous ceramic. Experiments in rats. Acta Orthopaedica Scandinavica, 60: 334-339.

47. Krebsbach PH, Mankani MH, Satomura K, Kuznetsov SA \& Robey PG (1998). Repair of craniotomy defects using bone marrow stromal cells. Transplantation, 66: 1272-1278.

48. Kon E, Muraglia A, Corsi A et al. (2000). Autologous bone marrow stromal cells loaded onto porous hydroxyapatite ceramics accelerate bone repair in critical-size defects of sheep long bones. Journal of Biomedical Materials Research, 49: 328-337.

49. Bruder SP, Kraus KH, Goldberg VM \& Kadiyala S (1998). The effect of autologous mesenchymal stem cell implants on the healing of canine segmental bone defects. Journal of Bone and Joint Surgery, 80: 985-986.

50. Quarto R, Mastrogiacomo M, Cancedda R, Kutepov SM, Mukhachev V, Lavroukov A, Kon E \& Marcacci M (2001). Repair of large bone defects with the use of autologous bone marrow stromal cells. New England Journal of Medicine, 344: 385-386. 